\title{
Economic Development and Environmental Sustainability in Bangladesh: A Study on Sustainable Development Goals (SDG)
}

\author{
Firoz Al Mamun ${ }^{1 *}$, Ahamad $\mathrm{Ali}^{2}$, Md. Chand $\mathrm{Ali}^{3}$
}

\author{
${ }^{1}$ Assistant Professor, Department of Political Science, Islamic University, Post code: 7003, Bangladesh \\ ${ }^{2}$ Lecturer, Department of General Educational Development, Daffodil International University, 4/2, Daffodil Tower, Sobhanbag, Mirpur Rd, Dhaka \\ 1207, Bangladesh \\ ${ }^{3}$ Assistant Professor, Department of English, Uttara University, House-4 \& 6, Road-15, Dhaka 1230, Bangladesh
}

DOI: $\underline{10.36347 / \mathrm{sjebm} .2020 . v 07 \mathrm{i} 09.005}$

| Received: 14.09.2020 | Accepted: 21.09.2020 | Published: 25.09.2020

*Corresponding author: Firoz Al Mamun

Abstract

Original Research Article

\begin{abstract}
The sustainability of conventional development in Bangladesh is under threat from the continuous degradation of natural and artificial resources, and from declining yields due to indiscriminate use of agro-technological sector. An NGO is pursuing efforts to promote ecological development with emphasis on better use of on-profitable resources and the reduction of external inputs. This paper examines the sustainability of two production systems in terms of their environmental soundness, economic viability and social acceptability based on empirical data collected through a household survey, development sector analysis, observations and discussions with key informants. Several indicators were selected to evaluate sustainability. However, no significant variations were found in other indicators such as millennium development and sustainable development in Bangladesh, economic zone and stability, risk and uncertainties, and food security. Although economic zone and financial return were found to be slightly higher in the conventional system, the economic return and value addition per unit of land did not show any difference. The findings suggest that ecological environment has a tendency towards becoming ecologically, economically and socially more sound than conventional system of development, as it requires considerably less agro-based development, adds more economic prosperity to the society, provides balanced food, and requires higher local inputs without markedly compromising output and financial benefits. Broad-policy measures, including the creation of mass awareness of adverse health effects of agro-based products, are outlined for the promotion of ecological security.

Keywords: Economic Development, Environmental Sustainability, Sustainable Development Goals (SDG), Bangladesh.

Copyright @ 2020: This is an open-access article distributed under the terms of the Creative Commons Attribution license which permits unrestricted use, distribution, and reproduction in any medium for non-commercial use (NonCommercial, or CC-BY-NC) provided the original author and source are credited.
\end{abstract}

\section{INTRODUCTION}

Traditional agro-based society provides livelihoods to more than two-thirds of the rural population in Bangladesh. Being one of the most densely populated countries in the world (865 persons $/ \mathrm{km}^{2}$ ), Bangladesh has one of the lowest land/person ratios; in 1995 [1, 2]. The high population growth (around 2\% annually) further reduces the availability of land for agriculture by creating increased demand for land for settlements, roads, industry, and other non-agricultural uses $[1,3,4]$. In view of the scarcity of land, emphasis has been given to increasing food production by intensifying the use of land, chemical fertilizers, industrial development, poverty reduction system, social development program, pesticides and water. Subsidies are provided for chemical fertilizers, pesticides and irrigation equipment to enable farmers to adopt these technologies for increasing crop yields [5]. This has caused major changes in cropping patterns of sustainability of environment, uses of development projects in agricultural inputs, and management of soil fertility has increased the economic growth but reduced the sustainability to the environment [5]. Use of chemical fertilizers increased six-fold between 1970 and 1990, and the use of pesticides increased about three-fold in just one decade, from 1982 to 1992 [6, 3].

In view of the problems arising from conventional agriculture in Bangladesh [7], a number of NGOs, namely, UBINIG (Policy Research for Development Alternatives), Proshika, and CARE Bangladesh have launched initiatives in different parts of the country to promote alternative development to sustain that emphasizes reduced use of external inputs, including agro-chemicals, economy, sustainability and increased use of local and on-farm resources in order to 
make the system both environmentally and economically sustainable [8]. Having recently been introduced, such initiatives are confined to certain pockets of the country. However, they are gaining importance gradually, as there is increasing awareness of the adverse health and environmental impact of conventional development. UBINIG is among a few pioneer agencies devoted to the promotion of what is locally called nayakrishiandolon or new agricultural movement, is a part of economic development of Bangladesh. This type of development emphasizes more use of on-profitable resources, including organic fertilizers, cropping diversification, mixed cropping, reduced use of chemical fertilizers, and no use of pesticides. Characteristically, this system is similar to what is normally known as ecological agricultural development [9], and thus hereafter is referred to as ecological agriculture. UBINIG started its activities in Delduar sub-district of Tangail district of Bangladesh in 1990. By June 1997, its program had expanded to 15 districts, and about 20,000 farm households were practising ecological farming $[8,10]$. Economic development depends on environment to sustain the project of development. Economic development and environmental sustainability are interconnected to sustain the natural environment. This research study is descriptive in nature. Mainly secondary sources like related books, articles, various documents and reports are used to analyze different aspects of this research topic. Internet sources have also been used for the research. The findings of the study are written in a more qualitative manner rather than in quantitative terms.

\section{OBJECTIVES OF THE RESEARCH}

- To find the interactions between economic development and environmental sustainability;

- To emphasize how the environment can be protected by following SDG's directions;

- To find how economic development will sustain as well as Environment.

\section{Economic Development and Environmental Sustainability: Conceptual Clarity}

Excessive and unbalanced use of agrochemicals has led to increased production costs and dependence on external inputs and energy, decline in soil productivity, contamination of surface and ground water, and adverse effects on human and animal health [11-13]. Therefore, there is growing emphasis on sustainable agriculture in response to concerns about the adverse environmental and economic impacts of conventional development [14]. In contrast, sustainable agriculture is viewed as low-input and regenerative [15], which makes better use of a farm's internal resources through incorporation of natural processes into agricultural production and greater use of improved knowledge and practices. It uses external and nonrenewable inputs to the extent that these are deficient in the natural environment [16].
Despite the diversity in conceptualizing sustainable development, there is a consensus on three basic features of sustainability. These are: (i) maintenance of environmental quality, (ii) stable plant and animal productivity, and (iii) social acceptability. Consistent with this, Yunlong and Smith [17] have also suggested that environmental sustainability should be assessed from the perspectives of ecological soundness, social acceptability, and economic viability. 'Ecological soundness' refers to the preservation and improvement of the natural environment. 'Economic viability' refers to maintenance of yields and productivity of crops and livestock, and 'social acceptability' refers to selfreliance, equality and improved quality of life.

Despite a broad consensus about the basic features of agricultural sustainability, there are fewer consensuses about which components should be given more importance in the assessment of sustainability. Depending on their particular academic or professional backgrounds, different people emphasize ecological development to sustain the economic growth. Lynam and Herdt, 1989 [18], Smith and McDonald, 1998 [19], Tisdell, 1996 [20] attach importance to the economic aspects of sustainability, such as net present value, benefit cost ratio and profitability. Recently, De Jager et al., 2001 [21], Tellarini and Caporali, 2000 [22] combined environmental and economic aspects in evaluating agricultural sustainability in Kenya and Italy respectively. However, few studies have assessed agricultural sustainability at the farm level covering all three main dimensions of sustainability [7].

\section{Different Options for Sustainability Ecological Sustainability}

Ecological sustainability was assessed based on five indicators: land-use pattern, cropping pattern, soil fertility management, pest and disease management, and soil fertility status. Land-use pattern was examined through the proportion of land under field crops, homestead and orchard. The seven major crops paddy, wheat, jute, potato, sugarcane, oilseeds and pulses were taken into consideration. Soil fertility management was evaluated based on the proportions of farmers using chemical and organic fertilizers, meaning farmyard manure and compost, and cultivating legume crops.

\section{Economic Sustainability}

Land productivity, yield stability and profitability from staple crops were considered the indicators of economic viability. Land productivity was measured through physical yield of crops. Crop yield data were collected through a household survey. Farm profitability was determined based on financial return, economic return and value addition per unit of land. Financial return was analyzed through gross margin, benefit/cost ratio and return per unit of labor. Economic return was calculated by deducting the subsidy given to agricultural inputs from gross returns to adjust the 
transfer payments. Value addition per unit of land was calculated by deducting the value of intermediate goods, such as chemical fertilizers, pesticides, diesel fuel and agricultural equipment, from the gross revenue, following APO 1994.

\section{Social Sustainability}

Social acceptability was assessed in terms of input self-sufficiency, equity, food security, and the risks and uncertainties involved in crop cultivation. Input self-sufficiency was determined on the basis of the ratio of local inputs cost to the total inputs cost. The higher the ratio of local inputs, the higher the input selfsufficiency [9]. In view of pervasive unemployment in rural areas of Bangladesh, the ability to generate employment within the system was considered as an indicator of equity. Family food security was assessed in terms of adequacy of food grain produced as well as farm households' ability to purchase food grain required for consumption. Risks and uncertainties were examined based on cropping diversification and diversity of agricultural income.

\section{Nature and Extents of Economic Development and Environmental Sustainability}

Widespread controversies exist on the delayed consequences of technological change or 'Green Revolution' technology in agriculture largely due to the approach utilized in the evaluation process and the extent of issues covered. Early evaluations, focusing on issues of production, employment, and income only, failed to account for the delayed consequences of technological change on regional variations, gender equity, poverty and the environment. The present study employed a holistic approach to evaluate the impacts of technological change in agriculture, specifically, on productivity, employment, gender equity, income distribution, poverty and the environment at the local level and on regional development, aggregate crop production and food grain sustainability at the national level. The overall hypothesis is that though modern agricultural technology increased production, employment and income, it has exacerbated income inequality, poverty, gender gap in employment, regional disparity and environmental degradation and is threatening food production sustainability. In this context, the research is designed with a blend of economic (crop input-output), biophysical (soil fertility) and behavioral (farmers' perception) analyses to capture the diverse issues (employment, income, income distribution, poverty and environment). Database of the study consists of time-series data for 47 years (19481994) and farm-level cross-section data of crop year 1996 collected from three agro-ecological regions including soil samples from representative locations and information on infrastructural facilities [23]. Economic principles and concepts are used as the basic tools of analysis and hypotheses are empirically tested using quantitative as well as qualitative techniques. The results of the analyses validated the concerns raised at the outset of the study. At the national level, though technological change played a significant role in raising regional agricultural development level, it has also contributed significantly to regional disparity with most regions being stagnant and underdeveloped over the past 20 years. Technological change also significantly contributed to aggregate crop productivity over the past 30 years. Returns to scale estimation using conventional factors revealed that 'constant return to scale' prevails in Bangladesh agriculture. Incorporation of technological and infrastructural factors in the estimation revealed 'increasing returns to scale'. But, declining productivity of modern rice, the major vehicle of technological change, is raising doubts on sustaining food production. The current increase in food production is largely due to switching from local to modern rice varieties and may not be sustainable in the long run. Trend analyses of 47 years of food grain (rice and wheat) production revealed that productivity is reaching a saturation value of $2,200 \mathrm{~kg} / \mathrm{ha}$, raising doubts on food production sustainability to meet the growing demand for food. Farm-level analysis of farmers' response to price changes revealed that probability of adopting modern technology increases with output price rise and decreases with input price rise. Intensity of modern technology adoption is higher in underdeveloped regions. Farmers have moderately inelastic response to price changes for foodgrain crops and highly elastic response for non-cereal crops. Consideration of the possibility of switching between local and modern food grain varieties, that is, allowing movement along a 'meta-production function' improved the elasticity estimates for food grain crops. Highly elastic response is observed for soil fertility improvement in food grain production and inelastic response for non-cereal crops. The response to infrastructural development and education work in opposite direction for these crop groups. While infrastructure development and farmers' education level increase input demand and output supply of non-cereal crops, these decreases input demand and output supply of food grain. At the local level, although modern agricultural technology significantly increased employment, input demand, prices and crop incomes, the gain from employment remained skewed in favor of men and income in favor of large/medium farmers. Also, significantly lower wage is paid to female labor, if hired, indicating further discrimination against women. Land and other resource owners are the highest beneficiaries of technological change. Production of modern varieties alone contributes $35 \%$ to total income inequality, thereby, indicating unexpected adversity of modern technology on income distribution. Poverty is estimated to be highest in 'high adopter villages' with $63 \%$ of population below poverty line, thus, reinforcing the unexpected adversity associated with technological change. 'Declining soil fertility', 'effect on human health', 'reduction of fish catch', and 'increase in insect, pest and disease attacks' are the major environmental impacts of technological change 
identified in the study regions as perceived by farmers [24]. Soil fertility positively influences prices, modern technology adoption, crop and agricultural income and negatively influences demand for labor, animal power and pesticides, and non-agricultural income. Infrastructure development also positively influences prices and non-agricultural income and negatively influences technology adoption and input demand (except animal power and agricultural credit). The 'medium adopter' villages characterized by diversified cropping system, larger with land endowment (0.96 ha/farm), better soil fertility and developed rural infrastructure revealed least income inequality and incidence of poverty. The gini-ratio of per capita income is estimated at 0.34 for the 'medium adopter' villages as compared to 0.44 and 0.45 for the 'high adopter' and 'low adopter' villages, respectively. Findings of this study, therefore, establish the superiority of 'medium adopter' villages with respect to distributional implications and challenge the conventional notion that high level of modern technology diffusion is the key to agricultural development and economic growth. Rather, a diversified cropping system including medium level of modern variety adoption yields higher income and causes least inequality and poverty. Therefore, based on the study results, an integrated agricultural development planning model comprising of six components: (1) limited modern technology diffusion, (2) crop diversification, (3) soil fertility management, (4) rural infrastructure development, (5) price policy and (6) economic diversification to non-agricultural activities, is proposed. The first three components are interlinked and needs to be implemented simultaneously. The remaining three components will smoothen the process by: (a) enhancing effective input delivery and output marketing systems through developed infrastructure, (b) responding to price signals through appropriate pricing policies, and (c) engaging in other income generating activities through economic diversification. A policy of animal power and output price subsidy is suggested to curb price risk and promote crop diversification. Also, crop insurance policies, marketing, transportation and infrastructure development are suggested to reduce yield and marketing risks. Human resources development, intensification of bottom-up planning and collaboration with non-governmental organizations (NGOs) are suggested as strategies to improve farmers' technical skills. Integration and close coordination among facilitators: relevant government agencies, NGOs, financial institutes and the farmers are identified as the key to achieving the goal of sustainable agricultural development [25].

\section{Economic Development and Environmental Sustainability Impacts on SDG's}

International development agenda has been actively led by the United Nations (UN) and its technical agencies and funds from their inception in the late 1940s. Till 1990s, the approach was fragmented and disjointed initiated by its specialized agencies or funds at various World Summits and Conferences to address three dimensions of development as economic, social, and environmental. The Millennium Declaration and Millennium Development Goals (MDGs) saw the convergence of development agenda of United Nations Development Program (UNDP); United Nations Environment Program (UNEP); World health organization (WHO); United Nations Children's Fund (UNICEF); United Nations Educational, Scientific and Cultural Organization (UNESCO); and other development agencies. Recently adopted Sustainable Development Goals (SDGs) reflect further strengthening convergence of the development agenda. The SDGs also strengthen equity, human rights, and non-discrimination.

\section{Economic Development and Environmental Sustainability Impacts on SDG's}

International development agenda has been actively led by the United Nations (UN) and its technical agencies and funds from their inception in the late 1940s. Till 1990s, the approach was fragmented and disjointed initiated by its specialized agencies or funds at various World Summits and Conferences to address three dimensions of development as economic, social, and environmental. The Millennium Declaration and Millennium Development Goals (MDGs) saw the convergence of development agenda of United Nations Development Program (UNDP); United Nations Environment Program (UNEP); World health organization (WHO); United Nations Children's Fund (UNICEF); United Nations Educational, Scientific and Cultural Organization (UNESCO); and other development agencies. Recently adopted Sustainable Development Goals (SDGs) reflect further strengthening convergence of the development agenda. The SDGs also strengthen equity, human rights, and non-discrimination.

\section{Economic Development in SDGs for Sustainable Environment}

The MDGs generated new and innovative partnerships, galvanized public opinion, and showed the immense value of setting ambitious goals. By putting people and their immediate needs at the forefront, the MDGs reshaped decision-making in the developed and developing countries alike. It helped to lift more than one billion people out of extreme poverty, to make inroads against hunger, to enable more girls than ever before to attend school, and to protect our planet. Yet inequalities persist and the progress has been uneven. The world's poor remain overwhelmingly concentrated in some parts of the world. Several women continue to die during pregnancy or from childbirth-related complications. Progress tends to bypass women and those who are lowest on the economic ladder or are disadvantaged because of their age, disability, or ethnicity. Disparities between rural and urban areas remain pronounced [26]. 
India has made a substantial improvement in MDGs but the progress is mixed. The under-five mortality rate (U5MR) has come down from 126 (1990) to estimated 48 not reaching the target of 42 by 2015 . However, the estimated child deaths have come down from 3.36 million (1990) to 1.2 million (2015) that translates to 3,300 child lives saved every day! U5MR in India is still above the world average (43), and is higher compared to Sri Lanka (10), Nepal (36), and Bangladesh (38). Infant mortality and neonatal mortality rates have come down to 38 (target 27) and 28 from 88 and 57, respectively. India achieved a maternal mortality rate (MMR) of 167 (2011-2013) and expected to reach 140 in 2015 down from 437 in 1990, which is well above the target of 109.If we go by the latest UN estimates of MMR of 560 in 1990,the target should be 140 and India is on track to achieve this target. The target of safe drinking water has been achieved in rural areas and is likely to be achieved in the urban areas as well. The target of sanitation is likely to be achieved in urban areas and missed in rural areas.

\section{The SGDs and Targets for Sustainable Development}

To create a new, people-centered, development agenda, a series of global consultations were conducted both online and offline. Civil society organizations, citizens, scientists, academics, and the private sectors from around the world were all actively engaged in the process. The SDGs include 17 goals and 169 targets. Indicators are expected to come out in March 2016. The 17 goals in abridged form are as follows:

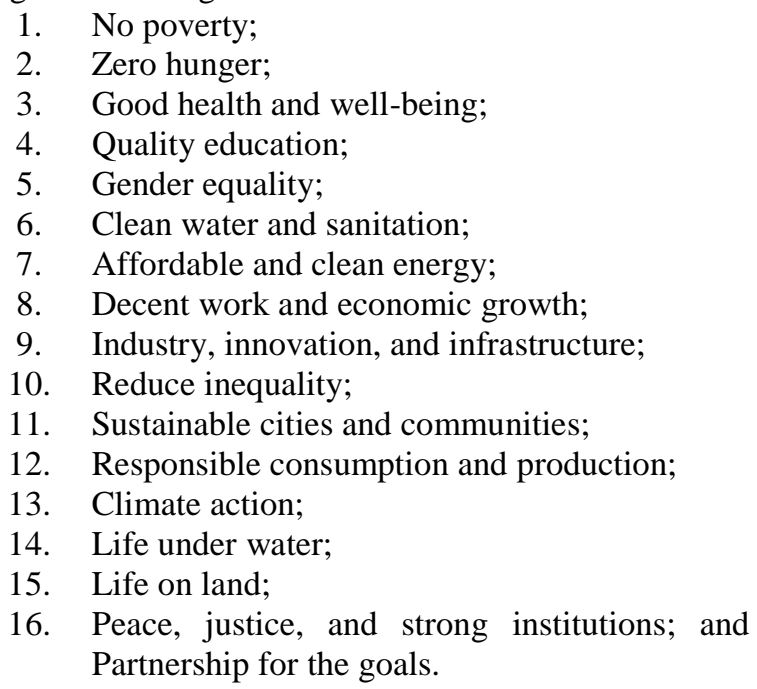

The targets are aspirational and global and that each government will set its own national targets taking into account the national circumstances. The SDGs can be broadly divided into three categories: First, an extension of MDGs that includes the first seven SDGs; second group is inclusiveness (jobs, infrastructure, industrialization, and distribution). It includes goals 8, 9, and 10; and the third group is on sustainability and urbanization that covers the last seven goals: sustainable cities and communities, life below water "consumption and production; climate action; resources and environment; peace and justice; and the means of implementation and global partnership for it" [27].

\section{Difference between SDGs and MGDs}

SDGs benefit from the valuable lessons learned from MDGs. These also carry forward the unfinished agenda of MDGs for continuity and sustain the momentum generated while addressing the additional challenges of inclusiveness, equity, and urbanization and further strengthening global partnership by including CSOs and private sector. They reflect continuity and consolidation of MDGs while making these more sustainable by strengthening environmental goals [28].

\section{There are seven major differences in MDGs and SDGs;}

1. MDGs were drawn up by a group of experts in the 'basement of UN headquarters' whereas SDGs have evolved after a long and extensive consultative process including 70 Open Working Groups, Civil Society Organizations, thematic consultations, country consultations, participation of general public through face-toface meetings and online mechanisms and door to door survey;

2. While MDGs were focused with only 8 goals, 21 targets and 63 indicators, SDGs include 17 goals with 169 targets. An expert analyses by noble laureates at Copenhagen consensus, suggest that if the UN concentrates on 19 top targets, it can get $\$ 20$ to $\$ 40$ in social benefits per dollar spent, while allocating it evenly across all 169 targets would reduce the figure to less than $\$ 10$. Being smart about spending could be better than doubling or quadrupling the aid budget;

3. MDGs had a focus on developing countries with funding came from rich countries. All countries, developed or developing, are expected to work towards achieving SDGs;

4. The pillars of human development, human rights and equity are deeply rooted in SDGs and several targets seven explicitly refer to people with disabilities, six to people in vulnerable situations, and two to nondiscrimination. These were not even mentioned in the MDGs; MDGs had 3 direct health goals, 4 targets and 15 indicators with emphasis on child, maternal mortality and communicable diseases. SDGs have one comprehensive goal emphasizing well-being and healthy living including NCDs;

5. MDGs had a time span of 25 years though adopted in 2002 baseline data for the year 1990 was used and some of the baselines were revised subsequently which shifted 'the goal post'. For the SDGs, the baseline is from 2015 estimates. It may be revised as more recent data becomes available; 
6. SDGs include a vision of building vibrant and systematic partnerships with private sector to achieve sustainable development. It builds on, UN Compact which was launched in year 2000 and IMPACT 2030;

7. MDGs had no concrete role for the Civil Society Organizations (CSOs), whereas SDGs have paid attention to this right from the framing stage itself with significant engagement of civil society actors.

\section{Challenges}

The four major challenges that need to be addressed for achieving the SDGs are as follows:

i. Some of the SDGs that have been costed show that the cost of the SDGs is huge. The rough calculations have put the cost of providing a social safety net to eradicate extreme poverty at about $\$ 66$ bn a year, while annual investments in improving infrastructure (water, agriculture, transport, and power) could be up to a total of $\$ 7$ globally. A major conference on financing for the SDGs, held in the Ethiopian capital Addis Ababa in July, failed to ease concerns that there will not be enough funds to meet the aspirational nature of the goals. It included a recommitment to the UN target on aid spending $0.7 \%$ of gross national income (GNI) set more than 40 years ago. Multilateral banks committed $\$ 400$;

ii. Maintaining peace is essential for development. A threat to international peace and stability by non-state actors is emerging as a major factor for both developed and developing countries. The recent crisis in Syria has forced 12 million people to leave their homes and made them refuges.

iii. Measuring progress: A number of targets in the SDGs are not quantified. The indicators for measuring progress have not yet been identified. Even if they limit to two indicators per target there will be 338 indicators to monitor and report. "Having 169 targets is like having no targets at all." Measurability will depend on the availability of data and capacity to measure them.

iv. Accountability: There was a lack of accountability for inputs into MDGs at all levels. This challenge needs to be addressed in SDGs.

At the international level, most of the developed countries have not met the target of allocating $0.7 \%$ of GNI to international aid in the last 40 years. The lack of priority in funds allocation within country budget has also been a problem during MDGs. Similar lack of accountability exists at ministry, state, and local administration level. If we take SDGs seriously the accountability needs to be strengthened at all levels.

\section{CONCLUDING REMARKS}

MDGs helped in mobilizing international community, leaders, politicians, civil society and sectoral ministries, and departments to focus on achieving these time-bound and measurably goals. We may not have achieved all these goals but have made a substantial progress in saving lives and improving quality of lives of millions of people within the country and globally. India has not made progress commensurate with its economic and environmental might and needs to do more. MDGs have been easy to relate, understand, communicate, implement, and monitor, whereas SDGs, though to some extent, are a continuation of MDGs, yet suffer from the weakness of being too many and unwieldy to implement and monitor. This has probably resulted from large consultative process where everyone wants to see their areas of interest included. Providing required funding to these a reality remains a challenge. There is a need to improve accountability from international level to local level. The next 15 years is likely to see unprecedented mobilization of resources and efforts to make the world a better place to live for "we the people", especially the marginalized and disadvantaged groups.

\section{REFERENCES}

1. Ali AMS. Population pressure, environmental constraints and agricultural changes in Bangladesh: examples from three agro ecosystems.1995.

2. Boyce JK, editor. Adjustment toward peace: economic policy and post-war reconstruction in El Salvador: a study commissioned by the United Nations Development Programme. UNDP; 1995.

3. Rahman S, Thapa GB. Environmental impacts of technological change in Bangladesh agriculture: farmers' perceptions and empirical evidence. Outlook on Agriculture. 1999 Dec;28(4):233-8.

4. FAO (Food and Agriculture Organization), 2000.

5. 1Hossain. Nature and Impact of the Green Revolution in Bangladesh, International Food Policy Research Institute \& Bangladesh Institute of Development Studies joint study. 1988.

6. Osmani SR, Quasem MA. Pricing and subsidy policies for Bangladesh agriculture. Research Monograph-Bangladesh Institute of Development Studies (Bangladesh). 1990.

7. Sachs J. From Millennium Development Goals to sustainable development goals. 2012.

8. Akter S, Hashmi MS. Plasto-hydrodynamic pressure distribution in a tepered geometry wire coating unit. InProceedings of the 14th Conference of the Irish manufacturing committee (IMC14), Dublin 1997 Sep (pp. 331-340).

9. 3Asaduzzaman, M., 1995. Resource degradation and sustainable development in Bangladesh: some preliminary estimates. 
10. Hirota S, Isozaki K, Moriyama Y, Hashimoto K, Nishida T, Ishiguro S, Kawano K, Hanada M, Kurata A, Takeda M, Tunio GM. Gain-of-function mutations of c-kit in human gastrointestinal stromal tumors. Science. 1998 Jan 23;279(5350):577-80.

11. Edwards III GC, Barrett A. Presidential agenda setting in Congress. InPolarized politics: Congress and the president in a partisan era 2000 (pp. 10933). Washington, DC: CQ Press.

12. Conway GR. Agroecosystem analysis. Agricultural administration. 1985 Jan 1;20(1):3155.

13. Biswas R, Devine KD, Flaherty JE. Parallel, adaptive finite element methods for conservation laws. Applied Numerical Mathematics. 1994 Apr 1;14(1-3):255-83.

14. Hansen BE. Inference when a nuisance parameter is not identified under the null hypothesis. Econometrica: Journal of the econometric society. 1996 Mar 1:413-30.

15. O'Connell RA, Mayo JA, Flatow L, Cuthbertson B, O'Brien BE. Outcome of bipolar disorder on long-term treatment with lithium. The British Journal of Psychiatry. 1991 Jul 1;159(1):123-9.

16. Pretty JN. Participatory learning for sustainable agriculture. World development. 1995 Aug 1;23(8):1247-63.

17. Yunlong C, Smit B. Sustainability in Chinese agriculture: challenge and hope. Agriculture, ecosystems \& environment. 1994 Jul 1;49(3):27988.

18. Tellarini V, Caporali F. An input/output methodology to evaluate farms as sustainable agroecosystems: an application of indicators to farms in central Italy. Agriculture, Ecosystems \& Environment. 2000 Jan 1;77(1-2):111-23.

19. Smith CS, McDonald GT. Assessing the sustainability of agriculture at the planning stage. Journal of environmental management. 1998 Jan 1;52(1):15-37.

20. Tisdell C. Bounded rationality and economic evolution. Books. 1996.

21. de Jager M, van Noort J, van Gent DC, Dekker C, Kanaar R, Wyman C. Human Rad50/Mre11 is a flexible complex that can tether DNA ends. Molecular cell. 2001 Nov 21;8(5):1129-35.

22. Tellarini V, Caporali F. An input/output methodology to evaluate farms as sustainable agroecosystems: an application of indicators to farms in central Italy. Agriculture, Ecosystems \& Environment. 2000 Jan 1;77(1-2):111-23.

23. New York, USA: United Nations Children's Fund (UNICEF); 2015. United Nations Children's Fund (UNICEF)

24. Ikerd JE. Sustainable Agriculture as the Rural Economic Development Strategy. 1999.

25. UN General Assembly. $69^{\text {th }}$ Session. Agenda Item 13(a) [Last accessed on 2015 Nov 09].

26. Report of the Intergovernmental Committee of Experts on Sustainable Development Financing 2014.

27. New Delhi, India: Social Statistics Division, Ministry of Statistics and Program Implementation, Government of India; 2015. Government of India. Millennium Development Goals. India Country Report; 19.

28. Philip G. (Ed.). Bangladesh Environment: Facing the 21st Century, Society for Environment and Human Development (SHED), Dhaka, 1998; 45. 